Ecosystems

December 2005; 8(8) : 899 - 910

http://dx.doi.org/10.1007/s10021-005-0011-z

(c) 2005 Springer Science+Business Media
Archimer, archive institutionnelle de l'Ifremer http://www.ifremer.fr/docelecl

The original publication is available at http://www.springerlink.com

\title{
Relating Species and Community Dynamics in an Heavily Exploited Marine Fish Community
}

\author{
Daniel E. Duplisea ${ }^{1^{\star}}$ and Fabian Blanchard ${ }^{2}$
}

\author{
${ }^{1}$ Institut Maurice-Lamontagne, Fisheries and Oceans Canada, CP 1000, Mont-Joli, Quebec, G5H, 3Z4, Canada \\ ${ }^{2}$ IFREMER, RH, BP 70, Plouzané Cedex, 29280, France \\ *: Corresponding author : Phone: 14187750881 Fax: 14187750740 duplisead@dfo-mpo.gc.ca
}

\begin{abstract}
We examined the dynamics of fish species and how they relate to species assemblage coherence in the heavily exploited Georges Bank fish community. Coherence is defined as reduced temporal variability of total assemblage biomass. We assumed that a higher degree of compensation hence coherence occurs within competitively coupled species assemblages; therefore, fisheries may directly alter the dynamics of certain targeted species sizes but assemblage structure will be relatively more stable owing to compensatory interactions. Species-sizes were grouped, based on negative covariance coupling in biomass time series from survey data. Assemblages representing benthic feeders were clearly identified by this method; furthermore, the most heavily exploited species-sizes were decoupled from other species-sizes suggesting that fisheries have diminished their potential to compensate or to be compensated for by competitive interactions. Biomass of species-sizes within known trophic guilds strongly compensated other guild-member biomass fluctuations if the diet of guild members was more specialized. This is an indication that more competitive conditions (more specialization) foster greater compensatory responses between competitors biomass fluctuations.
\end{abstract}

Keywords: goal function - thermodynamics - emergent property - energy flow - species replacement diversity-stability 


\section{Introduction}

Determining the impact of a single species fishery on aggregate fish community properties is a difficult problem which has received considerable attention (Duplisea and others 1997, Kerr and Dickie 2001, Jennings and others 2002, Rochet and Trenkel 2003, Trenkel and Rochet 2003). It is often assumed that fisheries control the dynamics of exploited fish communities, yet multispecies interactions can also strongly affect exploited fish species population dynamics (Magnússon 1995). Clearly, there is a need to understand species dynamics within a community perspective, even in the less than ideal situation where human activities affect outcomes.

Relating species and community dynamics is difficult because species are parts of ecosystems that contain many causal loops, which invalidates purely piecewise, species by species analyses and projections in all but the very short term (days to weeks). This is because ecosystems are complex self-organizing systems (Kay 1990). This does not mean that we cannot study community level phenomena, we can but we need to develop means to analyze structure at these higher levels rather than building from the base up.

Higher level system phenomena in fish ecology are usually examined using measures of the aggregated community such as total biomass (Duplisea and others 1997) biomass size spectra (Rice and Gislason 1996, Bianchi and others 2000) or mean trophic level of the community (Pauly and others 1998). These measures are able to show what the impacts of fishing have been on the aggregated community rather than just a single of group of species. These are useful phenomenological descriptors of systems but remain post hoc and provide little predictive capacity; however, these descriptors are still useful for drawing generalities on how fish assemblages are organized and how they are likely to respond to fishing.

One such generality that has arisen out of size spectrum studies is that total system biomass is much less variable than biomass of component species; furthermore, that biomass at size usually has a consistent pattern over time and space (Sheldon and others 1977). These patterns are present even in the face of large fisheries which undoubtedly affect community interactions; however, fish communities readily cope with fisheries perturbations in terms of preserving system energy flow function. The altered exploited fish community, however, may not be desirable in a socioeconomic sense owing to community shifts from commercially desirable species often to lower value and less charismatic species. It has also been shown that biomass in an ecological sub-grouping of benthic feeding fish, that contained evolutionarily distant species, was remarkably constant in biomass (Duplisea and others 1997). This preservation of the benthic fish collective structure suggests that species replacement occurs in fish assemblages such that if one species decreases in abundance one or more other species usually increase in abundance to compensate (Duplisea and others 1997). General phenomena such as these are referred to as emergent properties, and arise out of huge numbers of interactions between components but are difficult to predict simply from studying many components (Ulanowicz 1986).

Though it may be difficult to predict assemblage phenomena from component dynamics, it is still desirable to know how phenomena at the aggregated and disaggregated scales relate to each other. To this end, our knowledge of general phenomena have sometimes been taken as starting points for predicting system dynamics. 
For example, (Ulanowicz 1997) derived Ascendancy (A) as a measure of ecosystem maturity which accounts for number of interacting components and linkage strength between components. A is posited to be higher in old undisturbed systems than new or ephemeral systems. Another example is the system wide production to biomass ratio $(\mathrm{P} / \mathrm{B})$ which tends to be lower in mature ecosystems than in ecosystems in early successional stages (Margalef 1968, Matsuno 1978). Clearly one could maximize A, minimize $\mathrm{P} / \mathrm{B}$, or optimize any system property as a means to understand ecosystem organization.

Trophic competition is a known structuring mechanism in animal assemblages and species that have the greatest diet overlap are considered the strongest competitors with each other (Simberloff and Dayan 1991, Wilson 1999, Blanchard 2001). Groups of species with similar diets are referred to as trophic guilds. It is logical that one or more species in a trophic guild are most likely to compensate biomass fluctuations of other species in the same guild under competitive conditions of limited food resource. Hence, it is likely that given a time series of biomass of a species assemblage, the competitive species pairs are most likely to show combined biomass constancy and also a covariance structure that maintains that biomass (Cottingham and others 2001).

Given perturbations on individual species both natural and man induced, one might expect that compensation will occur between trophically similar species. This indeed has been observed in the Georges Bank fish assemblage (Murawski and Idoine 1992). We have used this observation of biomass constancy as a optimization criterion for determining which species interact and compensate each others' biomass fluctuations in order to achieve a relatively stable trophic guild biomass.

In the present marine fish study, we suggest that biomass constancy in systems is most likely to be apparent within competitively structured trophic guilds. We hypothesize that temporal variation in species biomass within a guild is most likely to be compensated by an opposite biomass fluctuation of one or more other species within the same guild; therefore, species within the same guild are most likely to have coupled covariance in biomass such that their aggregate biomass is relatively constant. Here we explore methods for understanding how biomass compensations may occur in an exploited fish community and how compensations relate to known trophic guilds of species-sizes.

Our study unfolds with in a series of steps where we:

1. develop a method which examines covariance between species and aggregates of other species to determine covariance groupings to be considered a tentative assemblage structures

2. examine how the most heavily exploited species in the system fit into these covariance groupings

3. from trophic guild structure determined by diet studies, test for significance of species compensation in that guild's biomass and examine results in relation to specialization versus generality of the guild diet.

This work sequence goes from the most general to the most specific in an attempt to understand how the Georges Bank fish community copes with perturbation such as fishing, then subsequently tease apart this response such that the aggregate response can in some manner be seen as a manifestation of individual species responses. 


\section{Methods}

Data

We used size and abundance data collected through statistically rigorous groundfish sampling surveys for the Georges Bank conducted by the Canadian Department of Fisheries and Oceans and for the North Sea collected by CEFAS. The Georges Bank survey is conducted in February each year using a stratified random sampling design (Doubleday 1981) and a Western IIa trawl with $19 \mathrm{~mm}$ cod-end mesh (Carrothers 1988). STRAP averages (Smith and Somerton 1981), area weighted averages based on a stratified random design, are reported here. We included fish only in the size range 15$120 \mathrm{~cm}$, as fish of this size should be captured consistently over the time series. We divided each species into size categories and calculated the biomass in each species-size category for each surveyed year (Appendix A). The size categories chosen were as in Garrison and Link (2000). For most species, small was from 10-20 cm, medium from 21$40 \mathrm{~cm}$, large from $41-80 \mathrm{~cm}$ and extra large $>80 \mathrm{~cm}$. Additionally, we report the potential impacts of directed commercial fishing on various species using the US National Marine Fisheries Service system which is based on ratio of the current biomass (B) to the estimated biomass at the maximum sustainable yield (Bmsy) point (Appendix A, Murawski and Almeida (2000)). The potential impact of by catch in the large scallop fishery on Georges Bank is also considered (Appendix A, NEFMC (2003)). We excluded species-sizes from the analysis if they appeared in less than half of the number of survey years as they are quite rare and therefore do not have much influence on the species-size covariance structure.

\section{Covariance grouping method}

We developed a method of grouping species-sizes based on their largest negative covariance (Table 1). Because the most tightly coupled competitors are most likely to show compensatory biomass trajectories, this should appear as the largest negative covariance in a community covariance matrix. Therefore, we chose a starting species and calculated the covariance between it and every other species-size group. We then aggregated with this starting species-size, the species-size that had the largest negative covariance minus the time series variance of the starting species group:

$\Phi=\operatorname{Min}\left(\operatorname{cov}_{i, j}-\operatorname{var}_{i}\right)$ for all $\mathrm{j}$

Where the species-size $\mathrm{j}$ which has the value $\Phi$ and is chosen to aggregate with $\mathrm{i}$ These two species-sizes are then removed from the matrix as separate entities but instead appear as a summed aggregate entity. The procedure is repeated until an amalgamation criterion is no longer satisfied. As our premise is that competitively determined groupings will have relatively more stable biomass than components, we chose an amalgamation termination criterion that dictates addition of a new species-size to the group must reduce the temporal variance of the aggregate and when it no longer does, terminate the amalgamation sequence. This termination criterion is consistent with the premise that species-sizes in the same guild are most likely to compensate each other biomass fluctuations in time. We measured the temporal variance of the aggregate as the CV over time. A group is defined at the termination of an amalgamation sequence. The procedure 
then looped with the reduced community matrix. After all species-sizes in the matrix were assigned to a group, the entire produce is looped using a different starting speciessize. This continued until every species-size had been the starting species once. The starting species-size loop is necessary because the procedure can be sensitive to starting species given that multiple species-size contingencies can exist and affect amalgamation order hence group membership.

The solution provided by this method is just one of several depending on the degree of contingency considered. That is, a hierarchical scheme where a new starting species is at every single step would account for more contingency but this is factorial problem and quickly could become computationally intractable. The degree of contingency in species interactions is like the contingency in an assembly sequence (Law and Morton 1996) and the greater the contingency, the greater the number of possible sequences, hence the greater the computation time. Our method has not accounted for the entire range of possible assembly sequences yet by allowing each species to appear as the starting species once, we have accounted for a great many possible outcomes.

If we started with $X$ number of species-sizes then we end up with $X$ number of realizations of the method which could theoretically all be the same or quite different depending on the strength of the contingent species-size covariance. We therefore, brought these together to form a dendogram by creating a distance matrix based on the number of times a species-size pair grouped together over all the realizations of the method. If these species were often grouped together, then they had a high affinity with each other (compensatory trajectories) were not overly affected by the presence or absence of other species. We call the strength of this affinity the group fidelity.

We examined the groups resulting from this analysis for their general diet preference, e.g. benthic feeders, to see if the grouping made sense. Additionally, because the method could potentially reveal the complementary biomass trajectories between predator-prey pairs, it is important to examine the relative body sizes of the group components where a prey and predator pair is unlikely to occur in groupings when the constituents are all of the same size category. Finally, we tested for spurious groupings by using a null model test (below). In this instance, this test is not one of significance but one of spuriosity. Because the groups were defined by complementary covariance, we expect a significant result for compensation in the null model test. If the null model test for complementary covariance does not confirm it, then it is valid to conclude that a particular group is a spurious group resulting from the method.

Null model (Monte Carlo) testing of the biomass constancy of known trophic guilds

Garrison and Link (2000) provided careful analyses of the diets of several Georges Bank fish species by size category. They performed multivariate analyses to group these into trophic guilds based on their diets. As we have a survey time series for Georges Bank species, we examined the hypothesis that biomasses of species-size groups within a Garrison-Link guild (GLG) are ordered such that the sum is compensatory; hence, temporal variability of biomass is reduced in a GLG more than would be expected if biomass configurations of GLG components were random.

Ho: biomass is randomly configured amongst guild components hence the CV of temporal variance within the guild is close to random, i.e. $\mathrm{CV} \approx 50 \% \equiv 5 \%>\mathrm{CV}$ $<95 \%$ 
Ha1: biomass is configured amongst guild components such that the sum within in years is relatively constant and the $\mathrm{CV}$ of temporal variance within the guild is significantly smaller than if biomass configurations were random, i.e. $\mathrm{CV} \leq 5 \%$ Ha2: biomass is configured amongst guild components such that the sum within years is significantly variable; hence, the $\mathrm{CV}$ of temporal variance within the guild is significantly greater than if biomass configurations were random, i.e. $\mathrm{CV} \geq 95 \%$

We examine these results in relation to the diversity of the diet of GLG members as a measure of prey switching potential, hence the generality of the diet and an indicator of the potential for a competition for food to occur amongst guild members. Diet diversity was calculated as the Shannon-Wiener index of fish stomach content differentiated into species (Garrison and Link 2000). By using the original matrix for null model testing we are controlling for the effects of random statistical cancellation (Margalef 1974, Doak and others 1998), sometimes referred to as the "portfolio effect" (Tilman and others 1998) and provides a useful analogy to better understand what is implied by the above hypotheses:

Ho is the null hypothesis where nothing interacts and guild components appear to be randomly co-occurring. Therefore, if the actual configuration of a guild's components' biomasses are neither more nor no less variable than those same biomasses randomly configured over all years, then we cannot reject the null model (i.e. no evidence of interaction is occurring). This is the classic portfolio effect where compensation in fluctuations is merely the result of random statistical cancellation and the greater the number of components, the greater the potential for overall constancy. Generally this is what a safe financial investing strategy aims to do, where the investment is spread over multiple sectors and regions to buffer individual fluctuations and addition of wealth comes about through overall economic growth rather than selection of particular fast growing subsectors or regions.

Hal is where the actual biomass configuration of components is less variable than one finds with random permutations of the component biomasses. Such a situation might occur in a financial portfolio by investing in different yet competing industries in the same sector. A simplistic example might be to invest in the long distance transportation sector with a two fold investment strategy such that both the high speed rail industry and the domestic airline industry split the total investment. The probability for one of these industries to increase when the other decreases is higher than for just two random industries over all economic sectors. This is a situation of hyperstability in the transportation portfolio, however is does not buffer against total decline in the transport sector owing to other external circumstances e.g. the general decline in the transportation sector following the events of 11 September 2001.

$\mathrm{Ha} 2$ is where the actual biomass configuration is more variable than random configurations of the biomass. In a portfolio this is called "putting all your eggs in one basket": there can be great rewards in particular sector upturns but there is also great loss on sector downturns. This is a boom-bust investing strategy. 


\section{Results}

\section{Time series covariance grouping method}

The time series covariance grouping method aggregated Georges Bank species into 9 major groups (Fig. 1). Application of the null model spuriosity test showed that speciessizes in groups 2-8 were not spurious groups $(\mathrm{p}<0.05)$ while groups 1 and 9 were. More than $75 \%$ of the constituent species in Groups 1, 6, 7 and 8 are strongly associated with the benthos. Other groups contained various pelagics and predators such as herring and dogfish, respectively; therefore, it is not possible to make a clear designation for these groups. Several species-sizes in this analysis were grouped with other species only with a very low group fidelity based on complementary time series biomass. Fishing activities strongly influences many of the lone species such as cod, flounders and skates. Most groupings have a fidelity of more than 0.8 indicating that time series complementarity between group and species-size biomass was relatively insensitive to starting speciessize.

Over all realizations of the method, $80 \%$ if the groups formed contained only one species-size while less than 5\% contained between 10 and 14 species sizes (Fig. 2a). Of the groups formed in all realizations, each contained less than $5 \%$ of the community biomass $90 \%$ of the time. On four realizations of the method, however, a single group was formed that contained more than $60 \%$ of the community biomass and on one occasion between 75 and $80 \%$ (Fig. 2b).

Null model guild temporal stability

The Monte Carlo method of examining variability of combined GLG biomass against the null model showed that two of the nine GLG on which the null model analysis could be performed had a significantly small $\mathrm{CV}$ value while five of the nine had a significantly large CV (Table 2). That is, the null hypothesis that species-size biomasses within GLG are independent of each other, was rejected in 8 of 9 cases thus suggesting that species biomass trajectories in GLG were either more or less variable than would be expected if biomasses of species-sizes were random.

The two GLG which had a significantly small CV (demersal benthivores and general piscivores) were also the multispecies GLG where diet diversity was also the smallest (Table 2), i.e. for which the specificity for a particular type of food was greatest. To the contrary, the six GLG with significant large CV usually had high diet diversity (less dependence on specific prey types). Four of these high CV GLG (three omnivore GLG and sea raven piscivores) consisted of only one biological species, though of two or three different sizes of each; hence, these cannot be considered multispecies guilds and direct recruitment-growth links exist between sizes of each of these species. Because of these links, it is not valid to search for compensation with the null model test when only one biological species constitutes a guild. The one remaining significantly high CV GLG, pelagic planktivores, consisted of mackerel, herring and small pollock and had a relatively high diet diversity. The pelagic planktivore GLG also had the highest temporal variance relative to other guilds and not just in relation to its null model $\mathrm{CV}$. The one guild for which the null hypothesis was not rejected was GLG I, shrimp and amphipod predators, which consisted of 11 species-sizes and had a high diet diversity and a small 
$\mathrm{CV}$ relative to other GLG. Therefore, the covariance structure of biomass time series of different species-sizes in GLG I could not be distinguished from a random assemblage.

\section{Discussion}

Phenomena such as conservative biomass at size distributions are commonly observed for exploited fish communities (Kerr and Dickie 2001). These phenomena or emergent properties, are thought to arise out of competitive interactions between species, sizes and life histories compounded with individual and population responses to perturbation. The overall sum of these interactions is identifiable (they emerge) and relatively constant. Emergent properties have been used to characterize systems and are now taking on a greater importance as ecological system indicators (Rochet and Trenkel 2003) as they represent the result of huge numbers of interactions without recourse to studying the dynamics of the components. The present study adopts a similar approach in that it recognizes structure at these aggregated levels (in this case the observation of biomass constancy in guilds). We go further, however, by imposing a pseudo-mechanism on sub-components where we aggregate using certain criteria in order to manifest the phenomenon of biomass constancy within guilds. Specifically, we have imposed an interaction criterion stating that species within the same guild are most likely to be competitors hence their biomass trends should be complementary with negative covariance. In so doing, we have created a model by which sub-community components must interact to come into congruence with observations at an aggregated level of biomass constancy. This model describes how various players could function together to produce this phenomenon of biomass constancy at an aggregated level.

Through imposing this criterion we have been able to show that the most heavily fished species in the Georges Bank fish community appear removed from other species in the system. We further show that species in more specialized trophic guilds show stronger compensatory covariance structure and species-size group time series characteristics are more similar for species within the same guild than for species between guilds.

The iterative method of aggregating species and groups of species with largest negative covariance created reasonable aggregations of species such as a group of fishes that live and feed on similar benthic food sources even though the constituent species were very different taxonomically (e.g. haddock, flounders and skates). This method indicated that some of the species which are most heavily exploited like large cod and haddock (Appendix A, Mertz and Myers (1998)) are also species which were rarely or never assigned to an aggregation of other species. This suggests that the biomass time series of these heavily exploited species are erratic relative to other species in the system and are, in a sense, out of harmony with the rest of the system. This method can produce spurious groups (e.g. groups 1 and 9) but application of the null model test can help to eliminate these. Some of the groups formed contain potential predator prey pairs, e.g. Group 7 contains both large spiny dogfish and small haddock whose complementary biomass trajectories are more likely to arise from a predator-prey coupling than a competitive coupling. Predator-prey groups appears less common than competitive groupings because fish predators and prey usually have a size difference of about 10:1 (Floeter and Temming 2003) yet most of the species-sizes assigned to the same group do not have this size differential suggesting that the groupings contain trophic competitors 
rather than predator-prey pairs. Additionally, it is more likely that predator and prey cycles lag in time hence they would be less apparent in the present method. Nevertheless, this is a potential confounding factor in the groupings and any applied use of these groupings would need to closely consider this.

Well established concepts such as competitive guilds (Simberloff and Dayan 1991, Wilson 1999) suggest that time series compensation should be manifest between species within a competitive guild. Competitive structuring of species' biomasses in the face of natural and fishery induced species fluctuation suggests that compensation in biomass is likely to occur between species within the same guild. Our null model tested for evidence that species-size biomass time series were not simply random. We found that the speciessize biomass configurations were dependent on the diversity of the guild members' diets. More compensation appeared to occur for guilds with specialized diets, suggesting that competition for the more specialized food resources forced a tighter coupling of competitors' biomass trajectories.

The pelagic planktivore guild showed the opposite of compensation as the guild biomass configuration was significantly more variable then expect if random. Such as situation can certainly arise when large scale drivers affect all components of a group in a similar manner. Such might be the case with an environmental driver such as temperature. Indeed most components of the Georges Bank pelagic planktivore community (mostly pelagic fishes) increase in biomass at the same time (Overholtz and others 2000). It is likely that shorter lived pelagics strongly affected by environmental drivers will not show trends in compensation consistent with a competitive structuring mechanism and more likely will appear to follow boom-bust cycles (Ha2 see methods).

We found that when a guild contained only one biological species, but with two or more sizes of that species, the configurations were more variable than random. This can be expected, as the biomass in these categories are not random as cohorts grow and move to larger sizes leading to autocorrelated time series. We did not attempt to remove the autocorrelation as this is essentially the signal we are using to create groups.

It has been speculated in the past that total community biomass variability is limited by variability of the energy input drivers and is less variable than component biomasses (Duplisea and others 1997). We found, however, that for the total sampled Georges Bank fish community the configurations of species-size biomasses in anyone year were such that the variability of the community over the time series was close to random. However, we showed that known trophic guilds within this community can be significantly nonrandom. We performed the same analysis with the English groundfish survey data of the North Sea (data courtesy of the Centre for Environment, Fisheries and Aquaculture Science, Lowestoft, UK) and found that the species-size biomass configuration was significantly more variable than would be expected if random. This indicates that the time trajectories of species-group biomasses are random on Georges Bank but trajectories are shared in the North Sea fishes. The degree of trajectory sharing between biomasses of species-sizes is not clear but likely it is related to the strength of environmental drivers in the systems and also fishing. Large multispecies fisheries exist in the North Sea and a diversity of economic subsidies keep fisheries open on so many species that the entire system dynamics may be far more a result of fishing than anything else.

The method of aggregating species with other species or groups of species based on their covariance relationship appeals to the concept of compensation within competitive 
guilds. The method explicitly considers that species compensation need not occur in a pairwise fashion but can and probably does occur diffusely within assemblages (Duplisea and others 1997). For this reason, it is not obvious that aggregations relevant to species compensation could be determined from standard multivariate statistical methods, which usually creates a multivariate pairwise distance matrix, applied to abundance data. Though this sort of method can reveal valuable information about co-occurrence of species in time and space (Mahon and Smith 1989) it is a statistical observation that is not necessarily theory driven. We performed a series of standard and non-standard multivariate clusterings of these data based on various sorts of pairwise distance measures and the results were quite different from the covariance method outlined here.

The strength of Lotka-Volterra competition in modeled communities does not affect the overall stability of the community (Ives and others 1999). Random factors mimicking environmental drivers were shown to be more important in the total biomass variability which accords with some of results found here. In experimental studies, however, interspecific competition has been shown to be a stabilizing factor for community biomass (Tilman 1996, Brown and others 2001). Brown et al. (2001) suggest that pairwise view of competition and species interaction is too simple to capture the complexity of competition in natural communities and therefore we need to examine natural assemblages in their entirety to understand how competition is manifest in communities.

Our use of a goal function of minimizing biomass variability is a key factor allowing us to determine group structure; however, is not the only goal function which can be used. Minimizing production to biomass ratio $(\mathrm{P} / \mathrm{B})$ may also be a more appropriate system goal function (Margalef 1968) and it is interpreted in a thermodynamic framework (Matsuno 1978). Certainly, improvement on searching for thermodynamic structures in ecosystem data can be made by considering one or more goals.

In studies such as this where we try to relate observations at the large scale to dynamics at the small scale can be identified as the inverse problem (Enting 2002) which pervades every scientific field where measurements are made on parts of larger systems. Identification of appropriate parts to measure, characterizing the nature of their interactions and relating some of these interactions to system dynamics is a very difficult problem but it is not intractable. Enting quotes in his abstract: "In systems characterized by high levels of contingency, inversion techniques, using observations as boundary conditions can provide an alternative to reductionist approaches". We have followed Enting here by using observation of biomass constancy to impose a condition by which interacting components must be bound in the entirety of their interactions. Rather than insisting that this pattern is a mechanism operating in the community we have simply used it to help us understand how species-size might interact and be affected by fisheries in an exploited fish community.

\section{Acknowledgements}

We thank Drs. Terry Done and Simon Jennings, and two anonymous referees for their valuable comments on the MS. We are grateful to the DFO Virtual Data Centre for providing easy access to a complicated survey dataset. 


\section{Literature cited}

Bianchi, G, Gislason, H, Graham, K, Hill, L, Jon, X, Koranteng, K, ManickchandHeileman, S, Paya, I, Sainsbury, K, Sanchez, F and Zwanenburg, K. 2000. Impacts of fishing on size composition and diversity of fish communities. ICES J. Mar. Sci. 57:558-571.

Blanchard, F. 2001. The effect of fishing on demersal fish community dynamics : an hypothesis. ICES Journal of Marine Science 58:711-718.

Brown, JH, Whitman, TG, Morgan Ernest, SK and Gehring, CA. 2001. Complex species interactions and the dynamics of ecological systems: long-term experiments. Science 293:643-650.

Carrothers, PJG. 1988. Scotia-Fundy groundfish trawls. Canadian Technical Report of Fisheries and Aquatic Sciences.

Cottingham, KL, Brown, BL and Lennon, JT. 2001. Biodiversity may regulate the temporal variability of ecological systems. Ecology Letters 4:72-85.

Doak, DF, Bigger, D, Harding, EK, Marvier, MA, O'Malley, RE and Thomson, D. 1998. The statistical inevitability of stability-diversity relationships in community ecology. Am. Nat. 151:264-276.

Doubleday, WG. 1981. Manual on groundfish surveys in the Northwest Atlantic. NAFO, Dartmouth.

Duplisea, DE, Kerr, SR and Dickie, LM. 1997. Demersal fish biomass size spectra on the Scotian Shelf, Canada: species replacement at the shelfwide scale. Can. J. Fish. Aquat. Sci. 54:1725-1735.

Enting, IG. 2002. Inverse problems in Earth System Science: a complex systems perspective. 62, ISBN 064306880 5, CSIRO.

Floeter, J and Temming, A. 2003. Explaining diet composition of North Sea cod (Gadus morhua): prey size preferencevs. prey availability. Can. J. Fish. Aquat. Sci. 60:140-150.

Garrison, LP and Link, JS. 2000. Dietary guild structure of the fish community in the Northeast United States continental shelf ecosystem. Mar. Ecol. Prog. Ser. 202:231-240.

Ives, AR, Gross, K and Klug, JL. 1999. Stability and variability in competitive communities. Science 286:542-544.

Jennings, S, Greenstreet, SP, Hill, L, Piet, GJ, Pinnegar, JK and Warr, K. 2002. Longterm trends in the trophic structure of the North Sea fish community: evidence from stable-isotope analysis, size-spectra and community metrics. Mar. Biol. 141:1085-1097.

Kay, JJ. 1990. A nonequilibrium thermodynamic framework for discussing ecosystem integrity. Pages 209-237 in CJ Edwards and HA Regier, editors. An ecosystem approach to the integrity of the Great Lakes in turbulent times. Great Lakes Fishery Commission, Ann Arbor.

Kerr, SR and Dickie, LM. 2001. The biomass spectrum: a predator prey theory of aquatic production. Columbia University Press, New York.

Law, R and Morton, RD. 1996. Permanence and the assembly of ecological communities. Ecology 77:762-775.

Magnússon, KG. 1995. An overview of the multispecies VPA -- theory and applications. Rev. Fish Biol. Fish. 5:195-212. 
Mahon, R and Smith, RW. 1989. Demersal fish assemblages on the Scotian Shelf, Norwest Atlantic: spatial distributions and persistence. Can. J. Fish. Aquat. Sci. 46:134-152.

Margalef, R. 1968. Perspectives in Ecological Theory. University of Chicago Press, Chicago.

Margalef, R. 1974. Diversity, stability and maturity in natural ecosystems. Pages 151-160 in WH Van Dobben and RH Lowe-McConnell, editors. Unifying Concepts in Ecology. Dr W Junk B.V. Publishers, The Hague.

Matsuno, K. 1978. Evolution of dissipative system: a theoretical basis of Margalef's principle on ecosystem. J. Theor. Biol. 70:23-31.

Mertz, G and Myers, RA. 1998. A simplified formulation for fish production. Can. J. Fish. Aquat. Sci. 55:478-484.

Murawski, S and Almeida, F. 2000. Status of fishery resource trends off the Northeastern United States: aggregate resource trends. New England Fisheries Science Council (NEFSC), Washington DC.

Murawski, SA and Idoine, JS. 1992. Multispecies size composition: A conservative property of exploited fishery systems? Changes In Biomass, Production And Species Composition Of The Fish Populations In The Northwest Atlantic Over The Last:79-85.

NEFMC. 2003. Atlantic sea scallop management plan, final amendment 10, table 73. New England Fisheries Management Council, Washington DC.

Overholtz, WJ, Link, JS and Suslowicz, LE. 2000. Consumption of important pelagic fish and squid by predatory fish in the northeastern USA shelf ecosystem with some fishery comparisons. ICES J. Mar. Sci. 57:1147-1159.

Pauly, D, Christensen, V, Dalsgaard, J, Froese, R and Torres, F, Jr. 1998. Fishing down marine food webs. Science 279:860-863.

Rice, J and Gislason, H. 1996. Patterns of change in the size spectra of numbers and diversity of the North Sea fish assemblage, as reflected in surveys and models. ICES J. Mar. Sci. 53:1214-1225.

Rochet, M-J and Trenkel, VM. 2003. Which community indicators can measure the impact of fishing? A review and proposal. Can. J. Fish. Aquat. Sci. 60:86-99.

Sheldon, RW, Sutcliffe, WH, Jr. and Paranjape, MA. 1977. Structure of pelagic food chain and relationship between plankton and fish production. J. Fish. Res. Board Can. 34:2344-2353.

Simberloff, D and Dayan, T. 1991. The guild concept and the structure of ecological communities. Annu. Rev. Ecol. Syst. 22:115-143.

Smith, SJ and Somerton, GD. 1981. STRAP : a user-oriented computer analysis system for groundfish research trawl survey data. Can. Tech. Rep. Fish. Aquat. Sci 1030.

Tilman, D. 1996. Biodiversity: Population versus ecosystem stability. Ecology 77:350363.

Tilman, D, Lehman, CL and Bristow, CE. 1998. Diversity-stability relationships: statistical inevitability or ecological consequence. Am. Nat. 151:277-282.

Trenkel, VM and Rochet, M-J. 2003. Performance of indicators derived from abundance estimates for detecting the impact of fishing on a fish community. Can. J. Fish. Aquat. Sci. 60:67-85. 
Ulanowicz, R. 1986. Growth and Development: Ecosystem Phenomenology. toExcel Press, IUniverse.com, Lincoln, NE.

Ulanowicz, R. 1997. Ecology, the ascendant perspective. Columbia University Press, New York.

Wilson, JB. 1999. Guilds, functional types and ecological groups. Oikos 86. 
Appendix A: List of species and their size divisions, trophic guild designation used in the present analysis and resource status. The trophic guild classification from Garrison and Link (2000). Blanks in the trophic guild designation indicates that species-size was not examined by Garrison and Link (2000). Resource status was assessed by comparing 1997 population status with modeled potential stock production in accordance with the standard procedure and rankings used by the US National Marine Fisheries Service (Murawski and Almeida 2000). ue = under exploited, fe $=$ fully exploited, oe $=$ over exploited. Bycatch impact potential is a ranking based on observed by-catch as a percentage of scallop catch by weight (NEFMC 2003) and qualitatively takes into account the abundance of the population.

\section{Common English name}

$\mathrm{L} \operatorname{cod}$

$M$ cod

$S$ cod

$\mathrm{XL}$ cod

M 4-beard

rockling

S 4-beard rockling

$\mathrm{L}$ haddock

$M$ haddock

$S$ haddock

XL haddock

$L$ white hake

$M$ white hake

$S$ white hake

$L$ red hake

$M$ red hake

$S$ red hake

L summer

flounder

M summer

flounder

L 4-spot flounder

M 4-spot flounder

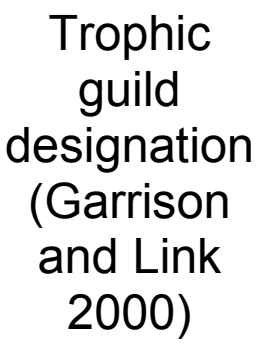

Gadus morhua

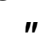

"

"

Enchelyopus

cimbrius

IVc
IVc
I
IVc

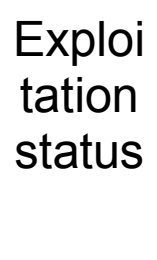

oe

"

II
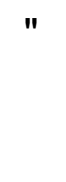

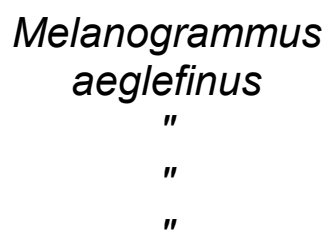

Urophycis tenuis

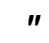

"

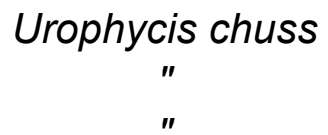

Paralichthys dentatus

Vb
IIIb
III
Vb
Vb
Vb
II
Vb
I
I

fe

$<0.1$

Potential catch scallop fishery $\%$

$\begin{array}{ll}0.1 & \text { low } \\ 0.1 & \text { low } \\ 0.1 & \text { low } \\ 0.1 & \text { low }\end{array}$
bycatch impact

0 low

0

low

$$
\text { " }
$$$$
<0.1
$$$$
<0.1
$$$$
<0.1
$$

low

low

low

"

0.1

low

oe

0.1

med

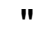

0.1

med

$"$

ue

0.1

med

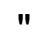

0.1

med

med

"

0.1

med

oe

0.8

med

"

0.8

med
Paralichthys oblongus

II

0.5

med

0.5

med 


\begin{tabular}{|c|c|c|c|c|c|}
\hline S 4-spot flounder & $"$ & I & & 0.5 & med \\
\hline L windowpane & $\begin{array}{c}\text { Scophthalmus } \\
\text { aquosus }\end{array}$ & II & fe & 0.5 & med \\
\hline M windowpane & " & Ila & $"$ & 0.5 & med \\
\hline S windowpane & $"$ & Ila & $"$ & 0.5 & med \\
\hline L silver hake & $\begin{array}{c}\text { Merluccius } \\
\text { bilinearis }\end{array}$ & $\mathrm{Vb}$ & oe & 0.1 & low \\
\hline M silver hake & $"$ & $\mathrm{Vb}$ & $"$ & 0.1 & low \\
\hline S silver hake & $"$ & I & $"$ & 0.1 & low \\
\hline L cusk & Brosme brosme & & & $<0.1$ & low \\
\hline L pollock & Pollachius virens & $\mathrm{Ila}$ & fe & $<0.1$ & low \\
\hline M pollock & $"$ & Ila & $"$ & $<0.1$ & low \\
\hline XL pollock & $"$ & IVc & $"$ & $<0.1$ & low \\
\hline L barndoor skate & Raja laevis & & fe & $0.1-11$ & very high \\
\hline M barndoor skate & " & & $"$ & $0.1-11$ & very high \\
\hline $\begin{array}{l}\text { XL barndoor } \\
\text { skate }\end{array}$ & $"$ & & $"$ & $0.1-11$ & very high \\
\hline $\mathrm{L}$ thorny skate & Raja radiata & $\mathrm{Vb}$ & $"$ & $0.3-11$ & very high \\
\hline M thorny skate & $"$ & Illa & $\mathrm{fe}$ & $0.3-11$ & very high \\
\hline S thorny skate & $"$ & I & $"$ & $0.3-11$ & very high \\
\hline $\mathrm{XL}$ thorny skate & $"$ & $\mathrm{Vb}$ & $"$ & $0.3-11$ & very high \\
\hline L smooth skate & Raja senta & & fe & $0.4-11$ & very high \\
\hline M smooth skate & " & & $"$ & $0.4-11$ & very high \\
\hline L little skate & Raja erinacea & Illa & fe & 11.7 & very high \\
\hline M little skate & " & 1 & $"$ & 11.7 & very high \\
\hline S little skate & $"$ & I & $"$ & 11.7 & very high \\
\hline L winter skate & Raja ocellata & $\mathrm{IVb}$ & $\mathrm{fe}$ & $1.3-11$ & very high \\
\hline M winter skate & $"$ & I & $"$ & $1.3-11$ & very high \\
\hline S winter skate & $"$ & I & $"$ & $1.3-11$ & very high \\
\hline $\mathrm{XL}$ winter skate & $"$ & $\mathrm{IVb}$ & $"$ & $1.3-11$ & very high \\
\hline L spiny dogfish & $\begin{array}{l}\text { Squalus } \\
\text { acanthias }\end{array}$ & IVa & oe & 0.4 & med \\
\hline M spiny dogfish & " & IVa & $"$ & 0.4 & med \\
\hline S spiny dogfish & $"$ & IVa & $"$ & 0.4 & med \\
\hline$M$ redfish & Sebastes marinus & & fe & $<0.1$ & low \\
\hline S redfish & " & & $"$ & $<0.1$ & low \\
\hline $\begin{array}{l}\text { M longhorn } \\
\text { sculpin }\end{array}$ & $\begin{array}{c}\text { Myoxocephalus } \\
\text { octodecemspinos } \\
\text { us }\end{array}$ & & & 0.1 & low \\
\hline $\begin{array}{l}\text { S longhorn } \\
\text { sculpin }\end{array}$ & $"$ & & & 0.1 & low \\
\hline L halibut & $\begin{array}{l}\text { Hippoglossus } \\
\text { hippoglossus }\end{array}$ & & & $<0.1$ & low \\
\hline M halibut & " & & & $<0.1$ & low \\
\hline
\end{tabular}




\begin{tabular}{|c|c|c|c|c|c|}
\hline XL halibut & $"$ & & & $<0.1$ & low \\
\hline L sea raven & $\begin{array}{l}\text { Hemitripterus } \\
\text { americanus }\end{array}$ & $\mathrm{Va}$ & & 0.3 & med \\
\hline M sea raven & " & $\mathrm{Va}$ & & 0.3 & med \\
\hline S sea raven & $"$ & $\mathrm{Va}$ & & 0.3 & med \\
\hline L monkfish & $\begin{array}{l}\text { Lophius } \\
\text { americanus }\end{array}$ & $\mathrm{Vb}$ & oe & 9.7 & very high \\
\hline M monkfish & $"$ & $\mathrm{Vb}$ & $"$ & 9.7 & very high \\
\hline S monkfish & $"$ & $\mathrm{Vb}$ & $"$ & 9.7 & very high \\
\hline L American plaice & $\begin{array}{l}\text { Hippoglossoides } \\
\text { platessoides }\end{array}$ & & oe & 0.1 & med \\
\hline $\begin{array}{l}\text { M American } \\
\text { plaice }\end{array}$ & $"$ & & $"$ & 0.1 & med \\
\hline $\begin{array}{l}\text { S American } \\
\text { plaice }\end{array}$ & " & & $"$ & 0.1 & med \\
\hline M witch flounder & $\begin{array}{c}\text { Glyptocephalus } \\
\text { cynoglossus }\end{array}$ & & oe & 0.1 & med \\
\hline $\begin{array}{l}\text { L yellowtail } \\
\text { flounder }\end{array}$ & $\begin{array}{l}\text { Pleuronectes } \\
\text { ferrugineus }\end{array}$ & Ila & fe & 0.9 & med \\
\hline $\begin{array}{l}\text { M yellowtail } \\
\text { flounder }\end{array}$ & $"$ & Illa & $"$ & 0.9 & med \\
\hline $\begin{array}{l}\text { S yellowtail } \\
\text { flounder }\end{array}$ & $"$ & I & $"$ & 0.9 & med \\
\hline L winter flounder & $\begin{array}{c}\text { Pseudopleuronec } \\
\text { tes americanus }\end{array}$ & Ila & oe & 0.5 & med \\
\hline M winter flounder & $"$ & Illa & $"$ & 0.5 & med \\
\hline S winter flounder & $"$ & 1 & $"$ & 0.5 & med \\
\hline $\begin{array}{l}\text { S Gulf Stream } \\
\text { flounder }\end{array}$ & $\begin{array}{l}\text { Citharichthys } \\
\text { arctifrons }\end{array}$ & & & $<0.1$ & low \\
\hline $\begin{array}{l}\text { M short finned } \\
\text { squid }\end{array}$ & Illex illecebrosis & & fe & $<0.1$ & low \\
\hline $\begin{array}{l}\text { S short finned } \\
\text { squid }\end{array}$ & $"$ & & $"$ & $<0.1$ & low \\
\hline M lumpfish & $\begin{array}{l}\text { Cyclopterus } \\
\text { lumpus }\end{array}$ & & & $<0.1$ & low \\
\hline L striped wolffish & Anarhichas lupus & & oe & $<0.1$ & low \\
\hline M striped wolffish & $"$ & & $"$ & $<0.1$ & low \\
\hline $\begin{array}{l}\text { XL striped } \\
\text { wolffish }\end{array}$ & $"$ & & $"$ & $<0.1$ & low \\
\hline L herring & Clupea harengus & IVa & ue & $<0.1$ & low \\
\hline M herring & $"$ & IVa & $"$ & $<0.1$ & low \\
\hline S herring & $"$ & Ilb & $"$ & $<0.1$ & low \\
\hline M shad & Alosa sapidissima & & fe & $<0.1$ & low \\
\hline S shad & $"$ & & $"$ & $<0.1$ & low \\
\hline
\end{tabular}




\begin{tabular}{|c|c|c|c|c|c|}
\hline M alewife & $\begin{array}{c}\text { Alosa } \\
\text { pseudoharengus }\end{array}$ & & oe & $<0.1$ & low \\
\hline S alewife & " & & $"$ & $<0.1$ & low \\
\hline L ocean pout & $\begin{array}{c}\text { Macrozoarces } \\
\text { americanus }\end{array}$ & & oe & 0.1 & d \\
\hline M ocean pout & $"$ & & $"$ & 0.1 & med \\
\hline S ocean pout & $"$ & & $"$ & 0.1 & med \\
\hline XL ocean pout & $"$ & & $"$ & 0.1 & med \\
\hline L mackerel & $\begin{array}{l}\text { Scomber } \\
\text { scombrus }\end{array}$ & Ilb & ue & $<0.1$ & \\
\hline M mackerel & $"$ & Ilb & $"$ & $<0.1$ & low \\
\hline S mackerel & $"$ & Ilb & $"$ & $<0.1$ & low \\
\hline
\end{tabular}


Table 1: stepped procedure of the covariance grouping method.

Step

Operation

1 create a matrix of biomass estimates over time for each species

2 choose a starting species

3 compute the covariance in the time series of this species with every other species

4 aggregate the biomass of the start species with the species that has the largest negative covariance with it

5 name this aggregated time series, aggregate 1

6 remove from the community matrix the component species that made up aggregate 1

$7 \quad$ start again at point 3 but with aggregate 1 as the chosen species

8 keep aggregating until the decrease in temporal variance (CV) of the aggregate caused by adding a new species is 0

9 when aggregation no longer reduces temporal variance, start the procedure again at 2 but with the reduced community matrix

10 follow steps from 3-9 until there are no species left that have not been assigned to an aggregate group

11 start at 2 again but with a different start species than has been chosen before.

12 go from 2 to 10 until every species in the matrix has been the start species

13 compute the number of times each pair of species appears with each other in the same group

14 create a clustering and dendogram based on the similarity matrix determined from 13 
Table 2: Results of Null model analyses of significance in temporal variability of biomass in known trophic guilds of species-sizes and the corresponding diet diversity of these guilds. Trophic guild classification and calculations of diet diversity were taken from data in (Garrison and Link 2000). Multispecies refers to biological species rather than just different size of the same species. Significant values $(>0.95,<0.05)$ are underlined.

Guild Symbol

Guild Description

Ila

Ilb

IIla

IIIb

IVa

$\mathrm{IVb}$

IVc

$\mathrm{Va}$

$\mathrm{Vb}$ shrimp and amphipod predators

pelagic shrimp predators

pelagic planktivores

demersal benthivores

benthic amphipod predator (haddock)

omnivores (dogfish)

omnivores (winter skate)

omnivores (cod)

piscivores (sea raven)

piscivores (general)
Diet Number of MultiDiversity Species- species sizes

3.68

3.35

3.04

1.83

1.26

3.14

3.36

3.92

2.47

2.55
CV

11

4

5

3

1

3

2

3

2

6

yes

0.29

yes $\quad 0.94$

2.22

yes

yes

0.63

no

no

0.96

1.14

0.98

0.55

0.23

no

yes value of CV

0.586

0.914

$\underline{0.986}$

$\underline{0.012}$ -

$\underline{0.993}$

1.000

1.000

$\underline{0.962}$

$1.56 \quad \underline{0.047}$


Figure Legends

Figure 1: a dendogram of Georges Bank species groups divided into 4 size classes based on similarities determined from time series covariance grouping method, where most dissimilar species (greatest negative covariance) were grouped with each other. Groups and the significance level for spuriosity (where $\mathrm{p}>0.05$ indicates a spurious grouping) shown on the figure.

Figure 2: (A) histogram of number of species-size categories from Georges Bank in groups and (B) proportion of biomass in groups as determined from the time series covariance grouping method. These histograms are produced from all realizations of the covariance grouping method rather than from the summary dendogram of those realizations shown in Fig. 1. 


\section{Group Fidelity (proportion of co-occurences)}

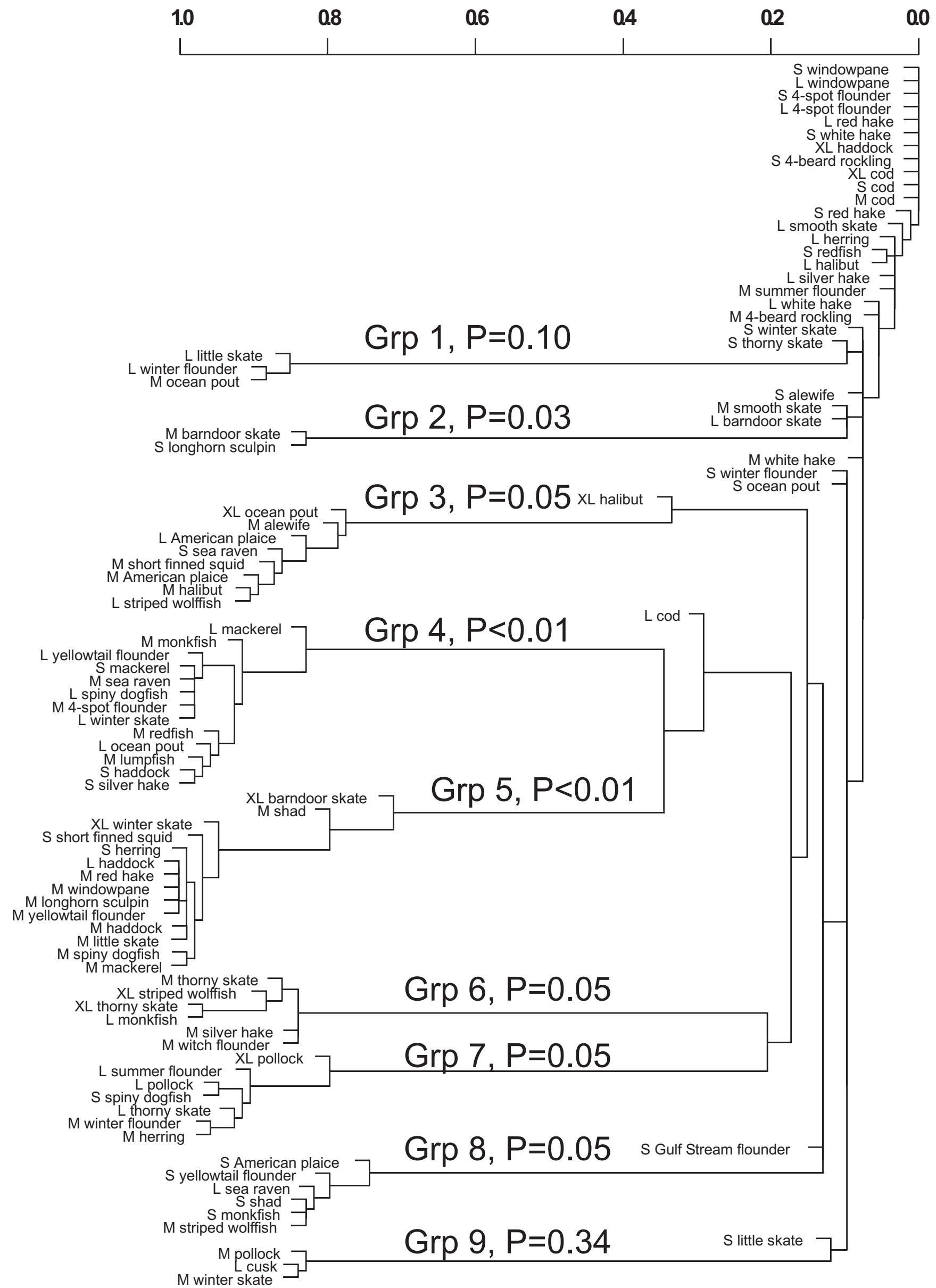


Figure 2
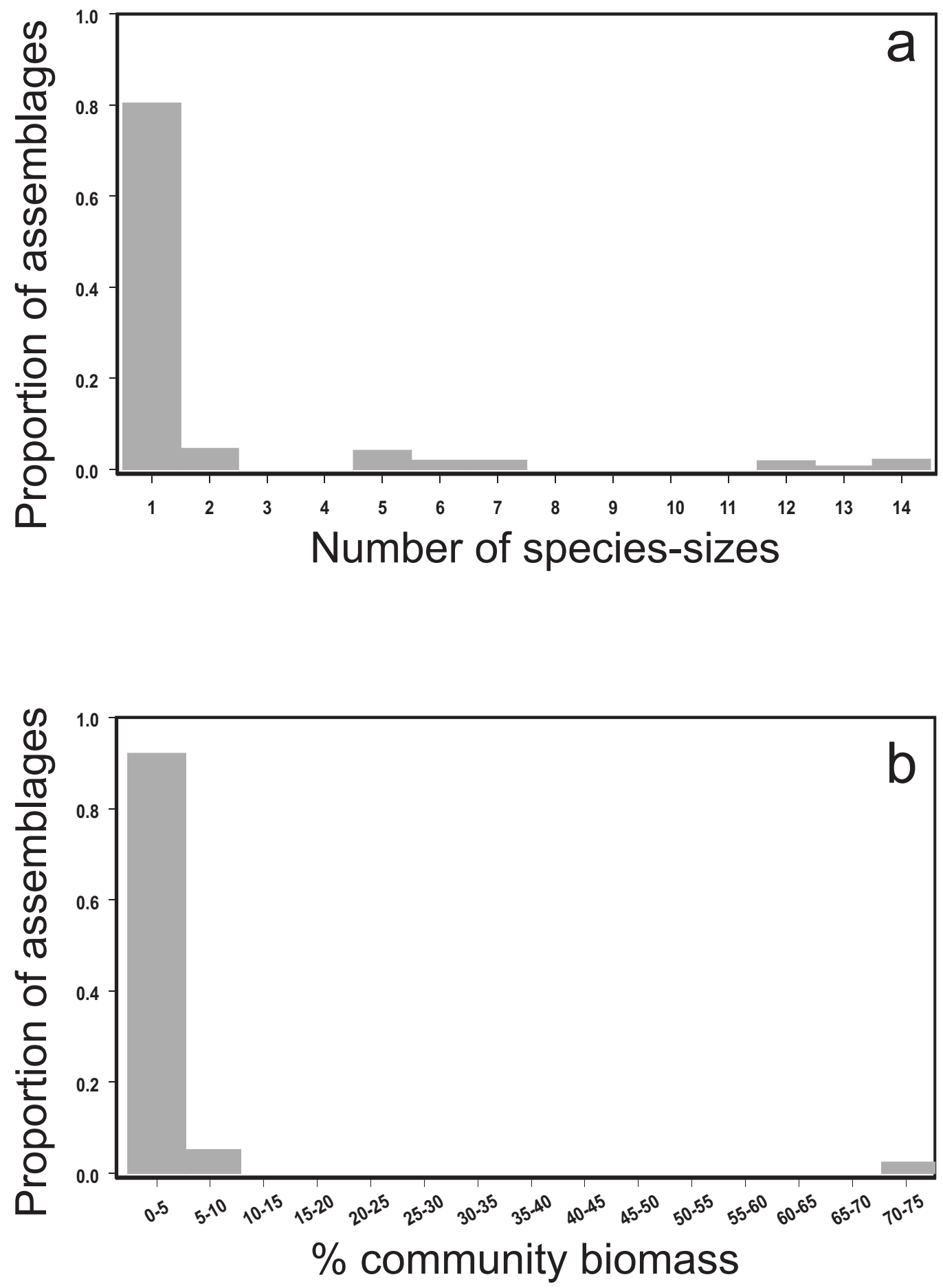